\title{
Are fire safe cigarettes actually fire safe? Evidence from changes in US state laws
}

\author{
Carl Bonander, ${ }^{1,2}$ Niklas Jakobsson, ${ }^{3,4}$ Finn Nilson ${ }^{1,2}$
}

\begin{abstract}
- Additional material is published online only. To view please visit the journal online (http://dx.doi.org/10.1136/ injuryprev-2017-042322).

'Department of Environmental and Life Sciences, Division of Risk Management, Karlstad University, Karlstad, Sweden ${ }^{2}$ Centre for Public Safety, Karlstad University, Karlstad, Sweden

${ }^{3}$ Norwegian Social Research (NOVA), Oslo, Norway ${ }^{4}$ Karlstad Business School, Karlstad University, Karlstad, Sweden
\end{abstract}

Correspondence to Dr Carl Bonander, Division of Risk Management, Department of Environmental and Life Sciences, Karlstad University, SE-651 88 Karlstad, Sweden; carl.bonander@kau.se

Received 8 January 2017 Revised 7 March 2017 Accepted 5 May 2017 Published Online First 19 June 2017

Check for updates

To cite: Bonander $\mathrm{C}$ Jakobsson N, Nilson F. Inj Prev 2018:24:193-198.

\begin{abstract}
Objective To estimate the effects of fire safe cigarette laws on fire mortality and cigarette-related fires in the USA.

Methods We examined the gradual implementation of the laws to identify their average effects, using difference-in-differences analysis to account for common year effects, time-invariant state effects, state-specific trends and observable time-varying state-level covariates. Results We found no statistically significant effects on all-cause fire mortality, residential fire mortality or cigarette-caused fire rates. The estimates for cigarettecaused fire deaths were significant under some specifications, but were not robust to the inclusion of state-specific trends or comparisons to effects on other cause-determined fires.

Conclusions Given the mixed state of our results, we conclude that previous claims regarding the effects of fire safe cigarette laws may be premature.
\end{abstract}

\section{INTRODUCTION}

Fires and fire-related mortality is a substantial societal problem across the globe in terms of both destruction of property and loss of life. ${ }^{1}$ One of the most prominent causes of fatal fires is the ignition of clothing, mattresses or other furniture by smoking materials. ${ }^{2}$ The population that is affected by these types of events are often considered a marginalised group of individuals that are likely hard to target with conventional prevention strategies (such as information campaigns or smoking bans). ${ }^{3}$ There is therefore a need for other types of evidence-based prevention measures.

An especially promising universal intervention, at least in theory, is a change in the construction of the cigarette that prevents it from smouldering when not being actively puffed on-a 'fire safe' cigarette that passively circumvents the actions of the individuals at risk. The allure of such an intervention is reflected in the large increase in countries that have implemented laws that ban the sale and production of cigarettes that do not meet these requirements over the last decade. ${ }^{4}$ In practice, fire safe cigarette laws are mandated on a standardisation basis, where the standards require all brands to undergo a test in which the cigarettes are lit and placed on a filter paper substrate. If cigarettes from a particular brand extinguish before smouldering their full length in $75 \%$ of the tests administered, they pass and are allowed to be produced and sold on the market. ${ }^{5}$ In effect, all smokers should be exposed to the intervention unless they roll their own cigarettes or buy smuggled ones, which we assume the average smoker at risk of dying in a fire does not. (For more detailed information on the technical details and the history behind the fire safe cigarette, see Baker et al for an overview. ${ }^{6}$ )

However, the empirical evidence on the effects of these laws on the occurrence of fires and fire mortality paints a mixed picture, with effect sizes ranging from $-40 \%$ to null effects. ${ }^{6}$ Most of these studies are based on case studies of countries or subnational jurisdictions, ${ }^{7-10}$ which may be problematic due to the possibility of publication bias in favour of statistically significant results in the expected direction. ${ }^{11}$ There are also a few more comprehensive evaluations that use data from all US states, but do not appear to sufficiently account for secular trends in their analyses, ${ }^{9} 12$ which is a cause for concern given the downward trending nature of the fire problem. ${ }^{13}$ The only truly credible and comprehensive analysis that we have been able to find is that of Markowitz, ${ }^{3}$ who in a more general study of the effects of changes in smoking policies on fire-related outcomes tested the effects of fire safe cigarette laws in the USA. She found no evidence of an effect on cigarette-caused fires in general, but did find statistically significant effects on cigarette-caused fire fatalities even after accounting for state and year effects. However, as she notes in the paper, the amount of postintervention years was small considering that the states had only recently started to implement fire safe cigarette laws when the study was conducted. The most troubling findings, however, are those of experimental studies testing the actual ignition propensity of fire safe cigarettes versus that of conventional ones in realistic lab settings (eg, when dropped on upholstery materials and couches). While they appear scarce, reports from the United States Consumer Safety Commission, ${ }^{14}$ the States Technical Institute of Sweden ${ }^{15}$ and tests conducted by Sasaki et $a l^{16}$ and Matsuyama et $a l^{17}$ have all found limited evidence that fire safe cigarettes actually differ from conventional cigarettes in ignition propensity. There is also literature on physiological effects of fire safe cigarettes compared with conventional cigarettes, and the behavioural and market responses to the introduction of these laws, that are outside the scope of this study. In summary, they show little to no effects on cigarette sales, intentions to quit or other changes in behavioural responses. ${ }^{18-20}$ In addition, there appears to be only limited increases in smokers' exposures to harmful constituents in fire safe cigarettes. ${ }^{21}$

Nonetheless, fire safe cigarette laws are still widely marketed as a successful strategy by, for example, WHO, even though they simultaneously 
request further research on the effectiveness of the intervention. $^{22}$ As of 2011, all US states have implemented fire safe cigarette laws. Given the contradictory state of the scientific evidence, we found it relevant to study the case of the introduction of these fire safe cigarette laws using more recent data, and a more comprehensive approach that uses multiple data sets and analytical approaches.

\section{MATERIALS AND METHODS Data}

We used data from several sources to compile a state-years panel data set containing data from 1999 to 2014 for all 50 states and the District of Columbia. Our main outcome measures were all-cause fire mortality, residential fire mortality, cigarette-caused fires and cigarette-caused fire deaths. For all-cause fire mortality and residential fire mortality, the CDC mortality database provides the most complete records for the study period. International Classification of Diseases codes X00-X09 (exposure to smoke, fire and flames) were used to identify relevant cases (we also used location codes to identify residential fires as this is where most cigarette-related fire deaths occur). However, since the database does not contain information on ignition source, we also turned to the National Fire Incident Data Reporting System (NFIRS) to obtain data on both cigarette-caused fires and fire deaths (as reported by fire departments). All states are covered by the system, but there are two major problems with these data that should be noted. The first is that the coverage is incomplete within each state (fire departments may report to the database voluntarily), and that the number of internally missing values on cause is large (41\% for all recorded fires and 54\% for fatal fires in the present data set). We have attempted to deal with these issues in our analysis (see below).

Covariate data were also collected from several sources. Data on the policy implementation dates were collected from CDC's State Tobacco Activities Tracking and Evaluation System, from which we also extracted data on adult smoking prevalence for the period 1998-2011 according to the Tobacco Supplement to the Current Population Survey (TUS-CPS). Since the latter is not conducted on a yearly basis, we also obtained state-years data on per capita taxable cigarette sales (in packs) from Orzechowski and Walker. ${ }^{23}$ Per capita ethanol consumption was obtained from the tables in Haughwout et al, ${ }^{24}$ per capita disposable income was extracted from the Bureau of Economic Analysis and population data (total population and share of the population aged $\geq 65$ years) was obtained from the U.S. Census Bureau. Summary statistics for all variables are presented in (supplementary appendix table A1).

\section{Statistical analysis}

We estimated the effects using Poisson regression models to accommodate for the count nature of all three outcomes (all-cause fire mortality, cigarette-related mortality and cigarette-related fires), using population size as the exposure offset variable. The presence of a fire safe cigarette law per state-year was coded as a dummy variable, where 0 indicates an absence of a state law for state $\mathrm{i}$ year $\mathrm{t}$ and 1 for time periods when a law is present. To check the sensitivity of the results to model specification, we estimated a range of different models for each outcome, from no trend adjustments, for example, naive beforeafter analyses, to more complex specifications. We present all these results below to show how the estimates change as we add more variables.
Our preferred specification of these models includes both state and year fixed effects to eliminate the influence of unobserved time-invariant confounders and common, federal time trends (often referred to as a two-way fixed effects model). ${ }^{25}$ Under a difference-in-differences framework, these models identify the average causal effect of the laws under a common trends assumption; that is, that there are no state-specific differential trends on the outcome variable. ${ }^{26}$ While this may not be true in many real-life applications, there are some potential ways to relax the assumption. One way is to include observable time-varying covariates that could serve as explanations for the diverging trends. To this end, we identified a set of observable explanatory factors that may explain some of the temporal trends based on previous literature. We included per capita disposable income, cigarette sales, ethanol consumption and the per cent of the population aged $\geq 65$ years as observable time-varying covariates. While smoker prevalence might have been preferable to cigarette sales, the prevalence data from TUS-CPS are not available for all state-years during the study period (1999-2014). Instead we used this variable to categorise states into quartiles based on smoker prevalence in order to test for moderating effects of prevalence on the policy impact estimates. For the outcome variables extracted from the NFIRS database, we also included the per cent of events with missing ignition source codes in order to alleviate some of the potential bias stemming from, for example, improvements in cause determination methods over time.

We recognise that it is unlikely that all relevant variables can be observed, and that those we do observe cannot be measured perfectly for the population at risk of cigarette-related fires. We therefore found it necessary to also account for unobservable reasons for differential trends as well. To do this, we included state-specific linear trends to capture some of the differences in trajectory. What the latter option does to the estimate, however, is that it limits its scope to a local effect at the time of the policy change. This can be compared with an abrupt effect in the interrupted time-series framework ${ }^{27}$ or a local average treatment effect in the regression discontinuity framework. ${ }^{28}$ In essence, it means that for the estimates from a state-specific trends model to be valid, we must assume that the effect occurs abruptly, that is, is not gradual or subject to other changes over time. ${ }^{26}$

A third analysis we employed was to estimate a dynamic effects model, which by inclusion of both leads and lags of the policy variable can serve as a test for whether or not the cause (policy change) occurs before the effect. ${ }^{29}$ It can also serve as a validity check for the common trends assumption, where we expect to see a horizontal trend in the effect estimates (with zero mean) the years prior to the policy change. Because of this, we checked for dynamic effects around a span of -4 to +4 years from the intervention since at least 4 years of postintervention data are available for all states. Beyond this time span, the amount of available states that can be used to estimation decreases exponentially since many states have a maximum of 4-5 postintervention years. If periods beyond this are used, biased estimates can be produced if the remaining states differ largely from the mean.

In the cause-specific models, we further complicated the analysis by estimating difference-in-difference-in-differences $(\mathrm{DDD})^{30}$ models to compare the effects on affected (cigarette-caused) fires and fire deaths to the contemporaneous effects on cause-determined events that were not related to smoking. Our hypothesis was that if the effects are causal, they should be larger for cigarette-related events than for fires caused by other factors. These models were specified as an extension of the two-way fixed effects model with main effects for state 
Table 1 Effects of fire safe cigarette laws on the incidence of all-cause fire mortality

\begin{tabular}{|c|c|c|c|c|}
\hline Model: & $\mathbf{I}$ & II & III & IV \\
\hline \multicolumn{5}{|c|}{ Panel A: all-cause fire mortality (any location) } \\
\hline Effect estimate (IRR, 95\% CI) & $0.78(0.75$ to 0.81$)$ & 0.95 (0.90 to 1.01$)$ & 0.95 (0.90 to 1.01$)$ & 0.95 (0.90 to 1.00$)$ \\
\hline State effects & Yes & Yes & Yes & Yes \\
\hline Year effects & & Yes & Yes & Yes \\
\hline Time-varying covariates & & & Yes & Yes \\
\hline State-specific trends & & & & Yes \\
\hline $\mathrm{N}$ states & 49 & 49 & 49 & 49 \\
\hline Average observations per state & 14 & 14 & 14 & 14 \\
\hline Valid state-years & 685 & 685 & 685 & 685 \\
\hline \multicolumn{5}{|c|}{ Panel B: all-cause fire mortality (residential fires) } \\
\hline Effect estimate (IRR, 95\% CI) & 0.80 (0.76 to 0.84$)$ & 0.94 (0.86 to 1.03 ) & 0.94 (0.86 to 1.02$)$ & 0.94 (0.86 to 1.02$)$ \\
\hline State effects & Yes & Yes & Yes & Yes \\
\hline Year effects & & Yes & Yes & Yes \\
\hline Time-varying covariates & & & Yes & Yes \\
\hline State-specific trends & & & & Yes \\
\hline $\mathrm{N}$ states & 46 & 46 & 46 & 46 \\
\hline Average observations per state & 11.9 & 11.9 & 11.9 & 11.9 \\
\hline Valid state-years & 547 & 547 & 547 & 547 \\
\hline
\end{tabular}

Poisson regression models with clustered-robust SEs were used to estimate the effects while accounting for correlated errors within states. The dependent variable is offset by population size (per state-year) in all models. The time-varying covariates included in models III-IV are per capita disposable income, cigarette sales, ethanol consumption and the per cent of the population aged $\geq 65$ years.

and year, state-specific trends and time-varying covariates, a law dummy, with the addition of interaction terms between all these variables and a dummy for event type (cigarette-caused or unrelated to smoking).

We present all effect estimates as IRR, which can be interpreted as relative effects. Residual autocorrelation and heteroscedasticity was accounted for using clustered-robust SEs. Uncertainty estimates were derived for the 95\% confidence range, assuming a conventional $\alpha$ value of 0.05 as a cut-off for statistical significance.

\section{RESULTS}

\section{Effects on all-cause fire mortality}

Beginning with the results for all-cause mortality (table 1, panel A), the estimates gave rise to a relatively straightforward interpretation. We found evidence of secular trends in the data, but once these were accounted for, no statistically significant evidence of an effect remained. If anything, there may have been a tendency towards small effects in regions of $-5 \%$ in all-cause fire mortality. The results did not change noticeably when accounting for the time-varying covariates. Restricting the data to residential fires, where most smoking-related fire deaths occur, did not change the results either (table 1, panel B).

\section{Effects on cigarette-related fires and fire deaths}

The results for the effects on cigarette-caused fires show a similar pattern; we found a statistically significant before-after reduction, but it appears that it can be explained, in its entirety, by the presence of secular trends (table 2, panel A, columns I-IV). A further validation of this is the results from the DDD model (table 2, panel A, column V), which shows no evidence of any differences in effect between cigarette-related fires and other cause-determined fires.

Contrary to the other outcomes, the results are more mixed when it comes to cigarette-caused fire fatalities. The results suggest that, while part of the before-after effects can be explained by common year effects and changes in the time-varying covariates, some evidence of an effect remains (table 2, panel B, columns I-III). However, these results are not robust to the inclusion of state-specific trends or compared with reductions in other cause-determined fires (table 2, panel B, columns IV and V).

\section{Dynamic effect estimates}

The results from the dynamic effects models for four leads and four lags appear to corroborate the results presented above (figure 1). These models also include year effects, state effects, state-specific trends and per capita disposable income, cigarette sales, ethanol consumption and the per cent of the population aged $\geq 65$ years. For the cigarette-specific outcomes, they also include the proportion of events with unknown ignition source. The all-cause fire mortality estimates are close to zero for all periods, except for a small positive shock in the period before enactment. The dynamics are similar for residential fire mortality, but the postintervention estimates are slightly larger. Estimates for the occurrence of cigarette-caused fires in general are steadily above the null value in the postintervention periods except for the third and fourth lags. Finally, the dynamic effects on cigarette-caused fire fatalities seem to indicate a gradually increasing effect from the time of intervention. However, the deviance from zero in the preintervention periods also gives rise to some concern regarding violations of the common trends assumption. For postintervention estimates to be valid, we would expect the estimates for the lead periods to have zero mean. Instead, it seems they are trending upwards for both cigarette-caused fires and fire fatalities.

\section{The influence of smoker prevalence on the effect estimates}

We present effect estimates for state groups categorised by smoker prevalence (in quartiles) to explore if the impact is larger for states with a higher prevalence of smokers in table 3 . The results are shown for models with state and year effects only (table 3, panel A) and models that also include state-specific linear trends (table 3, panel B). We obtained similar coefficients from both specifications. The general tendency is the same as in 
Table 2 Effects of fire safe cigarette laws on the incidence of cigarette-caused fires

\begin{tabular}{|c|c|c|c|c|c|}
\hline Model: & I & II & III & IV & v \\
\hline \multicolumn{6}{|c|}{ Panel A: cigarette-caused fires } \\
\hline Effect estimate (IRR, 95\% Cl) & 0.83 (0.71 to 0.96$)$ & 1.01 (0.83 to 1.23$)$ & 1.02 (0.85 to 1.22$)$ & 1.07 (0.87 to 1.31$)$ & $1.00(0.91$ to 1.11$)$ \\
\hline State effects & Yes & Yes & Yes & Yes & Yes \\
\hline Year effects & & Yes & Yes & Yes & Yes \\
\hline Time-varying covariates & & & Yes & Yes & Yes \\
\hline State-specific trends & & & & Yes & Yes \\
\hline DDD & & & & & Yes \\
\hline $\mathrm{N}$ states & 51 & 51 & 51 & 51 & 51 \\
\hline Average observations per state & 15.4 & 15.4 & 15.4 & 15.4 & 30.9 \\
\hline Valid state-years & 787 & 787 & 787 & 787 & 1574 \\
\hline \multicolumn{6}{|c|}{ Panel B: cigarette-caused fire fatalities } \\
\hline Effect estimate (IRR, 95\% Cl) & 0.66 (0.55 to 0.79$)$ & 0.70 (0.55 to 0.88$)$ & 0.74 (0.60 to 0.92$)$ & 0.82 (0.66 to 1.02 ) & 0.92 (0.74 to 1.14$)$ \\
\hline State effects & Yes & Yes & Yes & Yes & Yes \\
\hline Year effects & & Yes & Yes & Yes & Yes \\
\hline Time-varying covariates & & & Yes & Yes & Yes \\
\hline State-specific trends & & & & Yes & Yes \\
\hline DDD & & & & & Yes \\
\hline $\mathrm{N}$ states & 51 & 51 & 51 & 51 & 51 \\
\hline Average observations per state & 14.9 & 14.9 & 14.9 & 14.9 & 29.8 \\
\hline Valid state-years & 759 & 759 & 759 & 759 & 1518 \\
\hline
\end{tabular}

Poisson regression models with clustered-robust SEs were used to estimate the effects while accounting for correlated errors within states. The dependent variable is offset by population size (per state-year) in all models. The DDD model (column V) includes two observations per state-year; one for cigarette-related events and one for (causedetermined) events unrelated to smoking materials. This model includes main effects for all states, years, time-varying covariates and state-specific trends, as well as their interactions with event type (a dummy for cigarette-caused event or event unrelated to smoking). The time-varying covariates included in models III-V are per capita disposable income, cigarette sales, ethanol consumption and the per cent of the population aged $\geq 65$ years, as well as the proportion of events with unknown ignition source. DDD, difference-in-difference-in-differences model.

the models presented in tables 1 and 2, where we find limited evidence of an effect on all-cause fire mortality, residential fire mortality and cigarette-related fires, but a tendency towards an effect on cigarette-related fire mortality. While almost none of the estimates presented in table 3 is statistically significant, a common feature for all outcomes is that the point estimates are larger in the fourth quartile. It should however be noted that beyond this there is no consistent evidence of a dose-response relationship between smoker prevalence and effect size.

\section{Sensitivity analyses}

Estimates from linear fixed effects models gave rise to similar estimates and inferences as in the Poisson regression models presented above. Allowing for more flexible functional forms

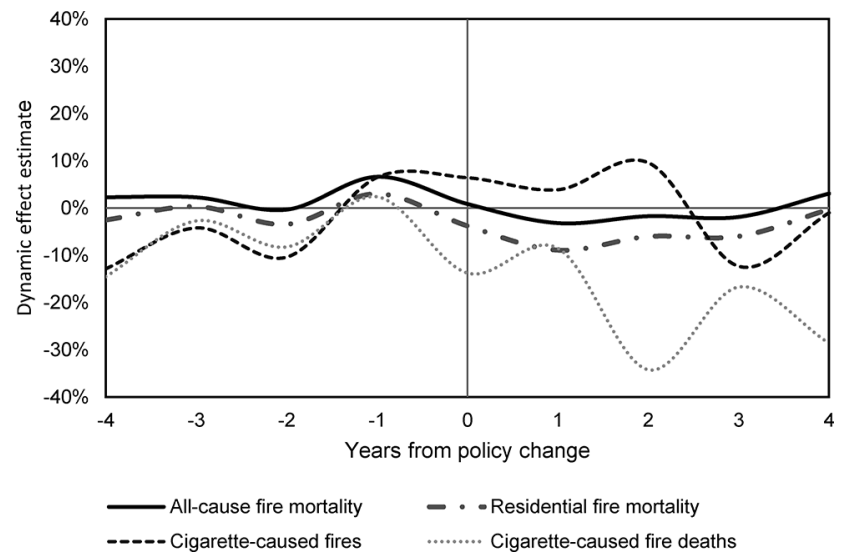

Figure 1 Dynamic effect estimates of fire safe cigarette laws in the USA, centred at the year of enactment. of the state-specific trends (quadratic and cubic) did not change the results from the models with state-specific linear trends to any meaningful extent. We obtained similar estimates when excluding states with gaps on the outcome variable.

One concern with the results presented thus far is the possibility that late adoption states may already be exposed to the treatment effects through spillovers (in the market share of fire safe cigarettes) stemming from early adoption states. A potential way to test this is to check if adoption order moderates the effect, where we would expect early adoption states to experience a larger impact than late adoption states. To this end, we defined a simple dummy variable for adoption order by dividing the sample in approximately half based on implementation year, where states that enacted the policy before 2009 are defined as early adopters and the rest as late adopters. The results from this exercise showed no indication that the effects were larger in the early adoption states (see online supplementary appendix table A2); in fact, the point estimates are larger for late adoption states for all outcome variables (the groups do not differ significantly from each other on any outcome). This pattern is reversed if we instead define those who adopted fire safe cigarette laws prior to 2010 as early adopters (still, they do not differ significantly).

\section{DISCUSSION}

Our results reinforce the mixed state of the evidence regarding the effects of fire safe cigarette laws, ${ }^{6}$ and despite finding an indication of an effect on cigarette-related fire mortality rates, we are still left with some unanswered questions. For instance, why would cigarette-related deaths have been affected while the cigarette-related fires in general have remained unchanged? That would imply that even though the quantity of fires is not 
Table 3 The effects of fire safe cigarette laws by smoker prevalence (in quartiles)

\begin{tabular}{|c|c|c|c|c|}
\hline & Quartile 1 & Quartile 2 & Quartile 3 & Quartile 4 \\
\hline \multicolumn{5}{|l|}{ Smoker prevalence (1999-2011) } \\
\hline Mean (\%) & 16.9 & 19.7 & 21.3 & 24.1 \\
\hline Range (\%) & $12.4-18.9$ & $19.0-20.5$ & $20.6-21.8$ & $21.9-27.5$ \\
\hline Outcome & \multicolumn{4}{|c|}{ Panel A: state and year effects only } \\
\hline All-cause fire mortality & 0.95 (0.90 to 1.01$)$ & 0.95 (0.86 to 1.06$)$ & 0.97 (0.84 to 1.12$)$ & 0.93 (0.80 to 1.08$)$ \\
\hline $\begin{array}{l}\text { All-cause fire mortality } \\
\text { (residential) }\end{array}$ & 0.98 (0.89 to 1.08 ) & 1.04 (0.80 to 1.34$)$ & 0.98 (0.69 to 1.40$)$ & 0.91 (0.77 to 1.08$)$ \\
\hline Cigarette-related fires & 1.02 (0.71 to 1.47 ) & 1.13 (0.98 to 1.30$)$ & 1.07 (0.70 to 1.62$)$ & $0.86(0.71$ to 1.05$)$ \\
\hline \multirow[t]{2}{*}{ Cigarette-related fire mortality } & 0.68 (0.48 to 0.96$)$ & $0.82(0.52$ to 1.27$)$ & $0.50(0.22$ to 1.19$)$ & 0.55 (0.30 to 1.01$)$ \\
\hline & \multicolumn{4}{|c|}{ Panel B: state effects, year effects and state-specific trends } \\
\hline All-cause fire mortality & 0.95 (0.90 to 1.01$)$ & 0.95 (0.86 to 1.06$)$ & 0.97 (0.84 to 1.12$)$ & $0.90(0.79$ to 1.03$)$ \\
\hline $\begin{array}{l}\text { All-cause fire mortality } \\
\text { (residential) }\end{array}$ & 0.97 (0.87 to 1.07$)$ & 1.01 (0.78 to 1.30$)$ & 0.96 (0.70 to 1.31$)$ & 0.92 (0.78 to 1.08$)$ \\
\hline Cigarette-related fires & 1.07 (0.76 to 1.52$)$ & 1.08 (0.98 to 1.19$)$ & $1.13(0.82$ to 1.54$)$ & 0.95 (0.73 to 1.22$)$ \\
\hline Cigarette-related fire mortality & $0.67(0.45$ to 1.00$)$ & 0.95 (0.60 to 1.50$)$ & 0.51 (0.15 to 1.68$)$ & $0.60(0.31$ to 1.15$)$ \\
\hline
\end{tabular}

Poisson regression models with clustered-robust SEs were used to estimate the effects while accounting for correlated errors within states. The dependent variable is offset by population size (per state-year) in all models. The coefficients are presented as IRR with 95\% Cls in parentheses.

affected, the likelihood of dying in a fire is reduced, something that is hard to explain given that the fire safe cigarettes are designed to lower the ignition propensity of cigarettes, which should also affect the likelihood of fires in general. Additional research into the mechanisms behind this difference may therefore be warranted, given that it is not simply a result of bias.

Even if there is some effect of these legislative changes, our study suggests that the magnitude is smaller than previously claimed. For comparison, Alpert et al found that the Massachusetts fire safe cigarette law was associated with a $28 \%$ reduction in the risk of cigarette-ignited residential fires (but no significant effects on cigarette-related fire deaths), ${ }^{7}$ and the $30 \%$ decline in smoking-related fire deaths in the USA between 2003 to 2011 has previously been attributed to the concurrent increase in the prevalence of fire safe cigarette laws. ${ }^{2}$ The European Commission also stated an expected effect of up to $-40 \%$ in their motivation for enforcing similar laws in the European Union, which is much larger than our estimates suggest. $^{31}$

\section{What is already known on the subject}

- Fire safe cigarettes are a universal intervention to prevent cigarette-related fire losses.

- Previous empirical evidence is based mainly on single-country studies and is mixed.

- Technical tests show little to no difference between fire safe or conventional cigarettes in realistic settings.

\section{What this study adds}

- We examine the gradual implementation of US state laws to conduct a comprehensive quasi-experiment.

- We use panel data methods to account for secular trends and state fixed effects.

- The results show only weak and inconsistent evidence of a population-level impact.

\section{Limitations}

There are some limitations to our study that should be noted. The lack of in-time randomisation of the legislative actions poses a potential threat to the internal validity of our effect estimates. The models used in the analysis incorporate time-invariant unobservable state and unobservable macro-level confounding factors via the inclusion of state and year fixed effects, as well as within-state changes on observable covariates. As a result, any remaining biases are limited to the state-specific variation on important unobserved confounders, measurement error or other events that are systematically correlated with the enactment of the state laws. However, the results did not change noticeably when state-specific trends were included, which suggests that differential trends may not have been a problem for the purposes of this study. The number of events with missing cause codes in the NFIRS data also calls for some caution in the interpretation of the results related to the cigarette-specific outcomes. While we attempted to alleviate this problem by adjusting for the proportion of events with unknown ignition source, and by comparisons to changes in cause-determined events that were unrelated to smoking in DDD models, these data quality issues may still pose a significant threat to the validity of our estimates. It should also be noted that while our models include state-level covariates, the ecological nature of this data means that we cannot be certain that we have captured the characteristics relevant to the true populations at risk, which is reflected in the fact the estimates do not change once they are included.

\section{CONCLUSIONS}

We echo the conclusions drawn in a report by the US Consumer Product Safety Commission. ${ }^{14}$ After finding that fire safe cigarettes appear to be similar to conventional cigarettes in terms of ignition propensity when tested on mattresses, they wrote that '... it is premature to conclude that the use of the [fire safe] cigarette alone will greatly reduce the threat of unintentional fires ignited by cigarettes involving mattresses and soft furnishings'. Coupled with our quasi-experimental results, and those of other technical studies, ${ }^{15-17}$ we find that there is a need for stronger evidence of the effects of fire safe cigarettes on ignition risk in realistic settings before drawing any final conclusions regarding their efficacy. 
Correction notice This paper has been amended since it was published Online First. Owing to a scripting error, some of the publisher names in the references were replaced with 'BMJ Publishing Group'. This only affected the full text version, not the PDF. We have since corrected these errors and the correct publishers have been inserted into the references.

Contributors All authors participated equally in the planning and design of the study. NJ designed the empirical strategy along with $\mathrm{CB}$, who collected the data and performed the analyses. All authors contributed to drafts of the paper.

Funding This study received financial support from the Swedish Civil Contingencies Agency (MSB) (grant number 2014-5283).

Disclaimer The funding source had no role in the design of the study, the analysis and interpretation of the data or the writing of, nor the decision to publish, the manuscript.

\section{Competing interests None declared.}

Ethics approval We used only publicly available, routinely collected (and aggregated) data from administrative registers. Thus, no patients were directly involved in this study, and ethical approval was therefore not required nor sought.

Provenance and peer review Not commissioned; externally peer reviewed.

Data sharing statement All data used for this study are publicly available, and the full data set can (and will) be shared upon request from the corresponding author (CB).

(c) Article author(s) (or their employer(s) unless otherwise stated in the text of the article) 2018. All rights reserved. No commercial use is permitted unless otherwise expressly granted.

\section{REFERENCES}

1 Beaglehole R, Irwin A, Prentice T, et al. The World Health Report 2004: changing history. Vol 2004. Geneva, Switzerland: The World Health Organization, 2004.

2 Hall JR. The smoking-material fire problem. Quincy, MA: National Fire Protection Association, 2013. Report No. USS10. http://www.nfpa.org/news-and-research/firestatistics-and-reports/fire-statistics/fire-causes/smoking-materials. (accessed 19 Aug 2016).

3 Markowitz S. Where there's smoking, there's fire: the effects of smoking policies on the incidence of fires in the USA. Health Econ 2014;23:1353-73.

4 World Health Organization. Fact sheet on reduced ignition propensity (RIP) cigarettes. 2014. http://www.who.int/tobacco/industry/product_regulation/factsheetreducedigni tionpropensitycigarettes/en/ (accessed 19 Aug 2016).

5 Gann RG, Measuring the ignition propensity of cigarettes. In: Proceedings of the Interflam Fire Science and Engineering Conference Vol 2007. London England, 2007, 144-55http://fire.nist.gov/bfrlpubs/fire07/PDF/f07068.pdf)

6 Baker RR, Coburn S, Liu C, et al. The science behind the development and performance of reduced ignition propensity cigarettes. Fire Sci Rev 2016;5:2.

7 Alpert HR, Christiani DC, Orav EJ, et al. Effectiveness of the cigarette ignition propensity standard in preventing unintentional residential fires in Massachusetts. Am J Public Health 2014;104:e56-e61.

8 Krasovsky KS. Reduced Ignition Propensity cigarette regulations and decline in fires, fire injuries and fatalities in Canada. Tob Control Public Health East Eur 2015;5.

9 Yau RK, Marshall SW. Association between fire-safe cigarette legislation and residential fire deaths in the United States. Inj Epidemiol 2014;1:10-16.

10 Bonander CM, Jonsson AP, Nilson FT. Investigating the effect of banning non-reduced ignition propensity cigarettes on fatal residential fires in Sweden. Eur J Public Health 2016;26:334-8.
11 Dickersin K. The existence of publication Bias and risk factors for its occurrence. JAMA 1990;263:1385-9.

12 Shults CA. Smoking-Related fires and the impact of the fire standard compliant legislation in the States: University of Tennessee, 2014. http://trace.tennessee.edu/cgi/ viewcontent.cgi? article $=4287 \&$ context $=$ utk_graddiss.

13 Fire Administration US. Fire Death Rate Trends: an International Perspective. Topical Fire Report Series 2012;12:1-8 https://www.usfa.fema.gov/downloads/pdf/statistics/ v12i8.pdf.

14 Mehta S. Cigarette ignition risk project. U.S. Consumer Product Safety Commission. https://www.cpsc.gov//PageFiles/139713/CIRProjectMemoApproved.pdf (accessed 19 Aug 2016).

15 Larsson I, Bergstrand A. Självslocknande Cigaretter - Teori Och Verklighet: SP Technical Research Institute of Sweden. http://publikationer.extweb.sp.se/user/default.aspx? Omradeld=4\#23544. (accessed 19 Aug 2016).

16 Sasaki F, Matsuyama K, Yanai E, et al. Experimental study on the effectiveness of RIP cigarettes to Fire Situation in Japan -Verification of RIP cigarettes effectiveness in light of the Lifestyle in Japan. Bull Jpn Assoc Fire Sci Eng 2013;63:67-78.

17 Matsuyama K, Uyama K, Sasaki F, et al. Experimental study on the effectiveness of RIP cigarettes to fire situation in Japan part 2-verification of effectiveness of RIP cigarettes in compressed futon and quasi-crevice setting. Bull Jpn Assoc Fire Sci Eng 2012:64:1-7.

18 Connolly GN, Alpert HR, Rees V, et al. Effect of the New York State cigarette fire safety standard on ignition propensity, smoke constituents, and the consumer market. Tob Control 2005:14:321-7.

19 O'Connor RJ, Giovino GA, Fix BV, et al. Smokers' reactions to reduced ignition propensity cigarettes. Tob Control 2006;15:45-9.

20 Seidenberg AB, Rees VW, Alpert HR, et al. Smokers' self-reported responses to the introduction of reduced ignition propensity (RIP) cigarettes. Tob Control 2012;21:337-40

21 O'Connor RJ, Rees VW, Norton KJ, et al. Does switching to reduced ignition propensity cigarettes alter smoking behavior or exposure to tobacco smoke constituents? Nicotine Tob Res 2010;12.

22 World Health Organization. WHO Study Group on tobacco product regulation: report on the Scientific Basis of tobacco product regulation: third Report of a WHO Study Group. World Health Organization 2009.

23 Orzechowski W, Walker R. The tax burden on tobacco. 2014. http://www.taxadmin. org/assets/docs/Tobacco/papers/tax_burden_2014.pdf (accessed 19 Aug 2016).

24 Haughwout SP, LaVallee RA, Castle I-JP. Apparent per Capita Alcohol Consumption: national, State and Regional Trends, 1977-2014: National Institute on Alcohol Abuse and Alcoholism, 2015. http://pubs.niaaa.nih.gov/publications/surveillance102/ CONS13.htm. (accessed 19 Aug 2016).

25 Wooldridge JM. Econometric analysis of Cross Section and Panel Data. MIT Press 2010.

26 Angrist JD, Pischke J-S. Mostly harmless econometrics: an Empiricist's Companion. Vol 1. Princeton: Princeton University Press, 2009.

27 Glass GV. Interrupted time series quasi-experiments. In: Jaeger RM, ed Complementary methods for research in education, 1997:589-608.

28 Imbens GW, Angrist JD. Identification and estimation of local average treatment effects. Econometrica 1994;62:467-75.

29 Cameron AC, Trivedi PK. Microeconometrics Using Stata. Vol 5. Texas USA: Stata press College Station, 2009

30 Long SK, Yemane A, Stockley K. Disentangling the effects of Health Reform in Massachusetts: how important are the special provisions for Young adults? Am Econ Rev 2010;100:297-302.

31 European Commision (EU). EU move to reduce cigarette ignited fires to save hundreds of lives each year (Pressrelease). http://europa.eu/rapid/press-release_IP-11-1342_en. htm (accessed 19 Aug 2016). 